\title{
Circulating endothelial cells in relapse and limited granulomatous disease due to ANCA associated vasculitis
}

\author{
A Woywodt, C Goldberg, T Kirsch, K de Groot, U Erdbruegger, H Haller, M Haubitz
}

Ann Rheum Dis 2006;65:164-168. doi: 10.1136/ard.2005.040980

See end of article for authors' affiliations

....................

Correspondence to: $\operatorname{Dr}$ A Woywodt, Division of Nephrology, Department of Medicine, Hannover Medical School, CarlNeuberg-Strasse 1, 30625 Hannover, Germany; Woywodt.Alexander@ MH-Hannover.de

Accepted

7 September 2005

Published Online First

8 September 2005

Objectives: To evaluate numbers of circulating endothelial cells (CECs) in ANCA associated vasculitis and compare vasculitic relapse with limited granulomatous disease.

Methods: Sixteen patients with vasculitic relapse of ANCA associated vasculitis and 12 patients with limited granulomatous disease due to Wegener's granulomatosis (WG) were studied. Six patients with newly diagnosed vasculitic disease and six patients with vasculitis with infectious complications were also studied. Twenty two patients in remission were studied, as were 20 healthy controls. Counting of CECs was performed with anti-CD146 driven immunomagnetic isolation and staining with Ulex Europaeus lectin 1(UEA-1).

Results: Patients with vasculitic relapse had markedly increased numbers of circulating endothelial cells (12-800 cells $/ \mathrm{ml}$, median $88 \mathrm{cell} / \mathrm{s} / \mathrm{ml})$ as did patients with newly diagnosed systemic vasculitis (20$216 \mathrm{cells} / \mathrm{ml}$, median 56 cells $/ \mathrm{ml}$ ). Patients with limited granulomatous disease due to WG had only slightly increased cell numbers $(4-44 \mathrm{cell} / \mathrm{s} / \mathrm{ml}$, median 20 cells $/ \mathrm{ml})$, which were similar to those of patients in remission (4-36 cells $/ \mathrm{ml}$, median $16 \mathrm{cell} / \mathrm{s} / \mathrm{ml})$. Numbers of CECs in patients with granulomatous disease were significantly lower than in those patients with relapse or new onset vasculitis $(p<0.001)$. Cell numbers in patients with relapse and new onset vasculitis declined with immunosuppressive treatment. Patients with infection had 4-36 cells $/ \mathrm{ml}$ (median 10 cells $/ \mathrm{ml}$ ). A cut off value of 20 cells $/ \mathrm{ml}$ for a positive result yielded $64 \%$ specificity and $95 \%$ sensitivity for active systemic vasculitis; the positive predictive value was $63 \%$ and the negative predictive value $95 \%$.

Conclusion: Markedly increased numbers of CECs discriminate active vasculitis from limited granulomatous disease and remission. These findings add further proof to the concept of CECs as a marker of ANCA associated small vessel vasculitis.

C irculating endothelial cells (CECs) are a new marker of microvascular injury. 'We have previously demonstrated the use of this marker in small vessel vasculitis associated with antineutrophil cytoplasmic antibodies (ANCA). ${ }^{2}$ In particular, we demonstrated large numbers of CECs in active disease, a decline of cell numbers with successful immunosuppressive therapy, and a necrotic/ procoagulant cell phenotype. Our previous study lacked data on patients with a relapse of systemic vasculitis and with limited granulomatous disease due to Wegener's granulomatosis (WG). Such information, however, is vital to the clinical use of this new marker. ${ }^{3}$ We have recently established an improved assay to facilitate the enumeration of CECs. ${ }^{4} \mathrm{We}$ were thus interested to measure CECs with this improved assay in patients with vasculitis. In this report we describe numbers of CECs in patients with relapse of ANCA associated small vessel vasculitis and in patients with limited granulomatous disease.

\section{SUBJECTS AND METHODS Subjects}

All patients were recruited at the division of nephrology, department of medicine, Hannover Medical School. The study protocol was approved after review by the local ethics committee and informed consent was obtained. We studied 62 patients with ANCA associated small vessel vasculitis. The diagnosis of ANCA associated vasculitis was established in accordance with the Chapel Hill classification. ${ }^{5}$ Relapse was defined by the recurrence or first appearance of at least one of the 24 items on the Birmingham Vasculitis Activity Score $(B V A S)^{6}$ that are indicative of active vasculitis (disease in the kidney, lung, skin, eye, motor nerve or gut). Limited granulomatous disease was defined as isolated disease of the respiratory tract with granulomatous inflammation, no active vasculitis on biopsy, and no constitutional symptoms. Stable remission was defined by a BVAS score of 0 for at least 12 months. ANCA titres and $C$ reactive protein (CRP) values were obtained using standard laboratory techniques. ANCA status was determined by immunofluorescence and enzyme linked immunoassay (ELISA) was used for target antigens.

Thirty nine patients had Wegener's granulomatosis (WG), 15 had microscopic polyangiitis (MP) and two patients had Churg-Strauss syndrome (CSS). cANCA was detectable in 40 patients and 12 patients were positive for pANCA while four patients had always been ANCA negative; of the four ANCA negative patients, two had biopsy proven CSS and two patients had biopsy proven WG. Disease activity was scored according to the Birmingham vasculitis activity score (BVAS). ${ }^{6}$

Sixteen patients had a relapse of vasculitis ( 11 male, 5 female; age 25-74 years, median age 56.5). Relapse occurred 1-33 years (median 4) after the initial diagnosis of ANCA associated vasculitis. Ten of these patients had WG, four

Abbreviations: ANCA, antineutrophil cytoplasmic antibodies; BVAS, Birmingham Vasculitis Activity Score; CECs, circulating endothelial cells; CRP, C reactive protein; CSS, Churg-Strauss syndrome; MP, microscopic polyangiitis; UEA-1, Ulex Europaeus lectin 1; WG, Wegener's granulomatosis 

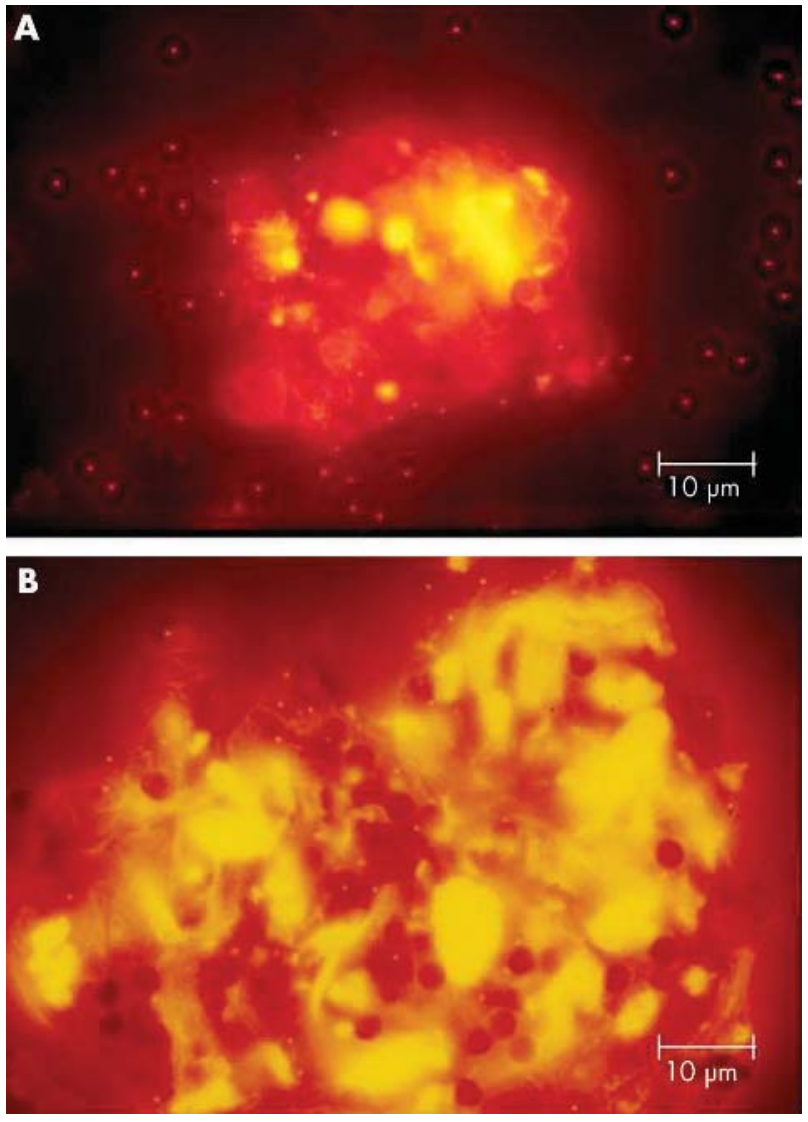

Figure 1 (A) Circulating endothelial cell and (B) conglomerate of cells.

patients had MP and two patients had CSS. Six patients (2 WG, 4 MP; 3 male, 3 female; age 37-76 years, median age 64) had new onset systemic vasculitis. Twelve patients had limited disease due to WG ( 5 male, 7 female; age $25-78$ years, median age 46). Eleven of these patients had a relapse and one patient had new onset disease. Twenty two patients (15 WG, 7 MP; 18 male, 4 female; age 36-74 years, median 62.5) were in stable remission for 1-31 years (median 6.5). Six patients with vasculitis ( 2 male, 4 female; age $47-77$ years, median 65.5) sustained an infectious complication during immunosuppressive therapy (1 urinary tract infection, l sepsis with unknown origin, 1 diverticulitis, 2 pneumonia, 1 gastroenteritis). Twenty healthy subjects ( 10 male, 10 female; age 26 to 77 years, median 53.5) were also studied.

In patients with relapse, new onset vasculitis, and granulomatous disease, blood samples were obtained within 48 hours of the start of treatment. For follow up, blood samples were obtained at the time of the initial presentation and after 1, 3, and 6 months, respectively.

\section{Counting of CECs}

CECs were isolated and enumerated as described in detail elsewhere. ${ }^{4}$ Briefly, anti-CD146 coated M-450 Dynabeads were obtained and stored at $4^{\circ} \mathrm{C}$ for a maximum of 4 weeks. Samples of peripheral blood were obtained with nontraumatic venepuncture, and we were careful to discard the first $7.5 \mathrm{ml}$. Blood (1 ml) was mixed with $1 \mathrm{ml}$ buffer (phosphate buffered saline, $0.1 \%$ bovine serum albumin, $0.1 \%$ sodium azide, and $0.6 \%$ sodium citrate) at $4^{\circ} \mathrm{C}$. FCR blocking agent $(20 \mu \mathrm{l})$ and $50 \mu \mathrm{l}$ antibody coated Dynabeads $(10 \mu \mathrm{g} / \mathrm{ml})$ were added and mixed thoroughly. Next, the sample was mixed in a head-over-head mixer for 30 minutes at $4^{\circ} \mathrm{C}$ and washed with buffer four times inside the magnet
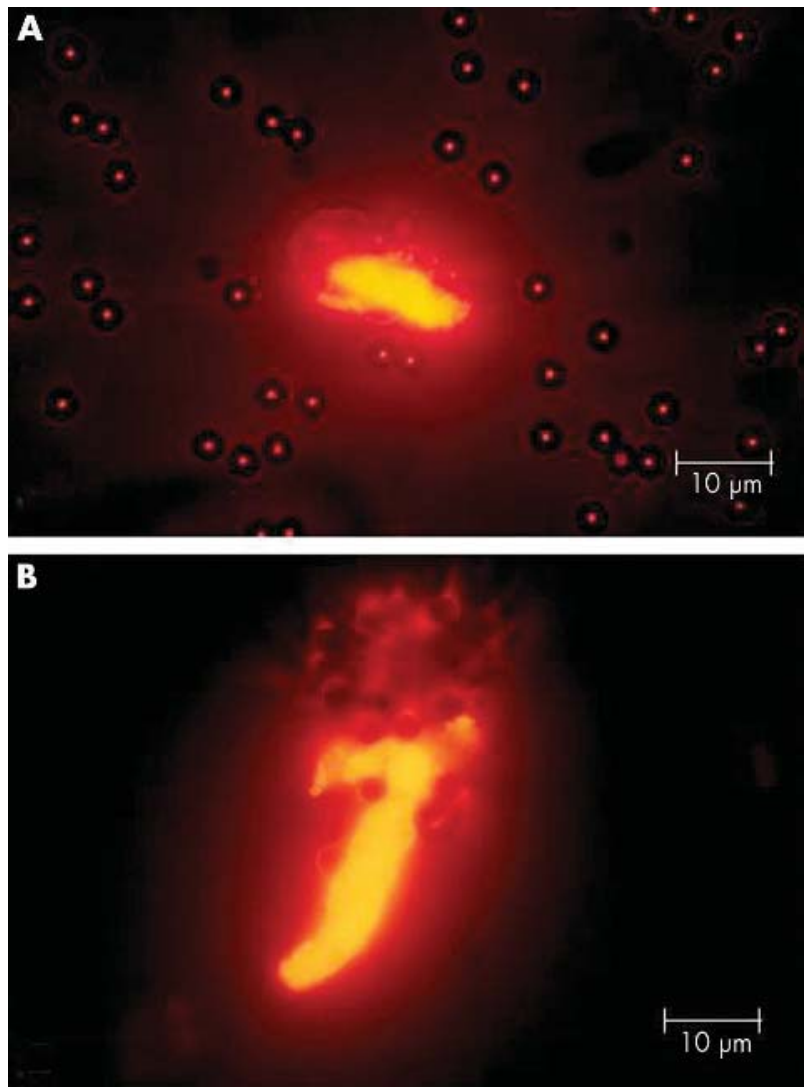

Figure 2 Smaller fragments of CECs.

at $4^{\circ} \mathrm{C}$. Between each washing procedure, the sample was flushed 10 times with buffer in a $100 \mu \mathrm{l}$ pipette. Ulex Europaeus lectin 1 (UEA-1) solution ( $100 \mu \mathrm{l} ; 2 \mathrm{mg} / \mathrm{ml}$ ) was added and incubated for 1 hour in darkness. The sample was washed twice and the cell-bead suspension finally dissolved in $200 \mu \mathrm{l}$ buffer. Cells were counted with fluorescence microscopy and a Nageotte chamber. Conglomerates were counted as one cell. The entire isolation and enumeration procedure took about 2 hours.

\section{Statistical analysis}

Differences between CEC numbers at the time of the initial presentation were evaluated with unpaired Mann-Whitney U testing (two sided). Kruskal-Wallis testing was used to detect significant differences between patients and healthy controls. Friedman's test was used to demonstrate statistical difference in endothelial cell numbers during follow up. Paired Wilcoxon testing (two sided) was applied to compare CEC numbers. Sensitivity, specificity, and predictive values were calculated using a $2 \times 2$ table. Correlation was calculated with Spearman's test.

\section{RESULTS}

\section{Cell morphology}

Using immunomagnetic isolation and subsequent UEA-1 lectin staining, we identified a population of cells as described previously. ${ }^{2}$ Cells were $10-100 \mu \mathrm{m}$ in size and had variable morphology (fig 1A). Nuclear carcasses, conglomerates of several cells (fig 1B), and smaller particles (fig 2) were also seen.

\section{BVAS scores, CRP values, and CEC numbers at time of} initial presentation

Patients with a disease relapse had BVAS scores between 8 and 20 (median 12.5); CRP levels ranged between 5 and 


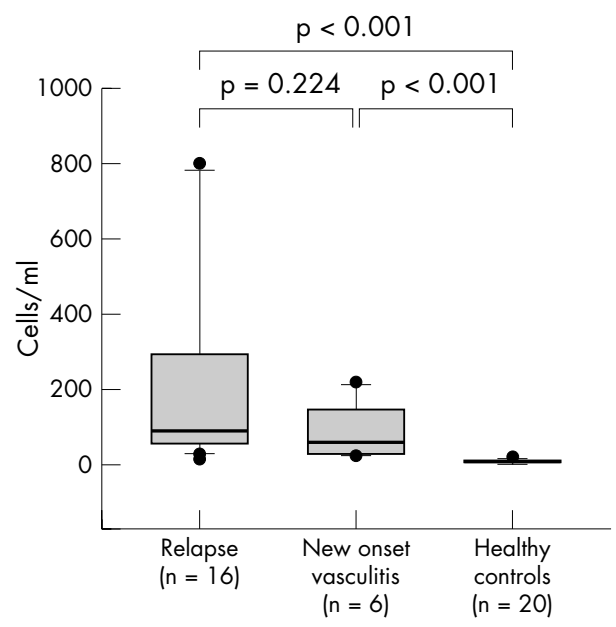

Figure 3 Cell numbers in patients with vasculitis and controls. The boundary of the box closest to zero indicates the 25th centile, a line within the box marks the median, and the boundary of the box farthest from zero indicates the 75th centile. Whiskers indicate the 90th and 10th centiles while dots indicate outlying points.

$336 \mathrm{mg} / \mathrm{l}$ (median $26 \mathrm{mg} / \mathrm{l}$ ). CEC numbers were between 12 and 800 cells/ml (median 88 cells/ml). Patients with WG had between 48 cells $/ \mathrm{ml}$ and 608 cells/ml (median 146 cells $/ \mathrm{ml}$, $\mathrm{n}=10$ ) while patients with MP had 12-184 cells/ml (median 64 cells $/ \mathrm{ml}, \mathrm{n}=4$ ). No formal comparison was made owing to the small number of patients.

In patients with new onset vasculitis, BVAS scores were between 9 and 21 (median 19) and CRP ranged between 5 and $152 \mathrm{mg} / \mathrm{l}$ (median $51 \mathrm{mg} / \mathrm{l}$ ). The numbers of CECs in these patients were between 20 and 216/ml (median 56 cells/ $\mathrm{ml}$ ) and did not differ from cell numbers in patients with disease relapse $(\mathrm{p}=0.224)$.

Patients with limited granulomatous disease had BVAS scores between 4 and 12 (median 7.5). CRP levels ranged from 5 to $175 \mathrm{mg} / \mathrm{l}$ (median $17.5 \mathrm{mg} / \mathrm{l}$ ). Numbers of CECs were between 4 and 44 cells $/ \mathrm{ml}$ (median 20 cells $/ \mathrm{ml}$ ), which was significantly lower than in those patients with relapse or

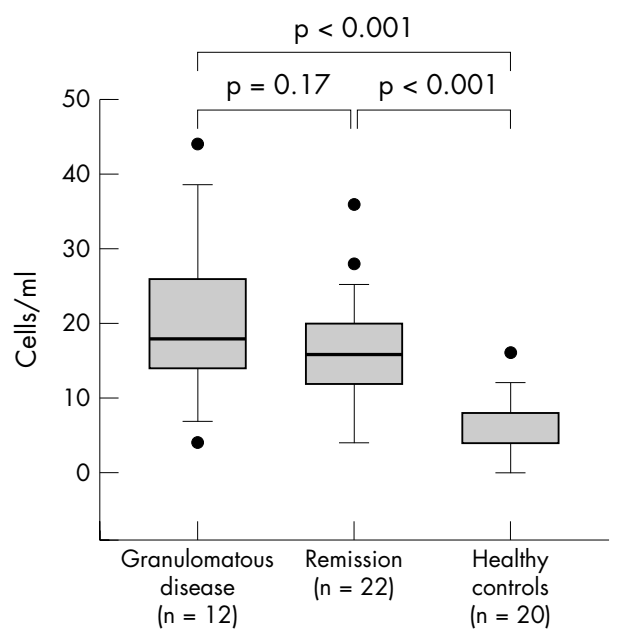

Figure 4 Cell numbers in patients with granulomatous disease, remission, and healthy controls. The boundary of the box closest to zero indicates the 25th centile, a line within the box marks the median, and the boundary of the box farthest from zero indicates the 75th centile. Whiskers indicate the 90th and 10th centiles while dots indicate outlying points. new onset vasculitis $(\mathrm{p}<0.001$ when compared with patients with relapse).

Patients in remission all had a BVAS score of 0. CRP levels were 1 to $37 \mathrm{mg} / \mathrm{l}$ (median $2 \mathrm{mg} / \mathrm{l}$; $\mathrm{p}<0.001$ when compared with patients with relapse). Numbers of CECs were between 4 and 36 cells $/ \mathrm{ml}$ (median 16 cells $/ \mathrm{ml}$ ) and did not differ significantly from counts in patients with limited granulomatous disease $(\mathrm{p}=0.17)$.

A weak correlation was found between ANCA titres and CEC numbers at presentation (Spearman's rank correlation $\left.r_{s}=0.26, \mathrm{p}=0.05, \mathrm{n}=56\right)$. ANCA negative patients $(\mathrm{n}=4)$ appeared to have similar cell numbers to ANCA positive patients $(n=52)$, although no formal statistics were performed owing to the small number of patients in the ANCA negative group. Two ANCA negative patients with vasculitic relapse had 260 and 25 cells/ml, respectively, while one ANCA negative patient with granulomatous disease had 44 cells $/ \mathrm{ml}$ and one ANCA negative patient in remission had 4 cells $/ \mathrm{ml}$.

Patients with vasculitis and infection had $4-36$ cells $/ \mathrm{ml}$ (median 10 cells $/ \mathrm{ml}$ ). CRP values were $5-85 \mathrm{mg} / \mathrm{l}$ (median $26 \mathrm{mg} / \mathrm{l}$ ). No formal comparison with patients with vasculitis without infection was performed.

Healthy controls had 0-16 CECs/ml (median 4 cells/ml), which was significantly less than all other groups $(\mathrm{p}<0.001)$. Figures 3 shows cell numbers in patients with relapse and new onset vasculitis compared with healthy controls. Figure 4 shows cell numbers in patients with limited granulomatous disease and remission compared with healthy controls.

We calculated sensitivity, specificity, and predictive values of a positive test result among patients with relapse, new onset vasculitis, and limited granulomatous disease, only using cell numbers at the time of initial presentation. A cut off value of 20 cells $/ \mathrm{ml}$ for a positive result yielded $64 \%$ specificity and $95 \%$ sensitivity. The positive predictive value was $63 \%$ and the negative predictive value $95 \%$. Changing the cut off value to 30 cells $/ \mathrm{ml}$ increased specificity to $88 \%$ and decreased sensitivity to $81 \%$, respectively. The positive predictive value was $81 \%$ and the negative predictive value $88 \%$.

\section{Follow up data}

Fourteen patients with a relapse of vasculitis were available for follow up. In these patients, Friedman's test showed a significant decline $(\mathrm{p}<0.02)$ in cell numbers after the start of

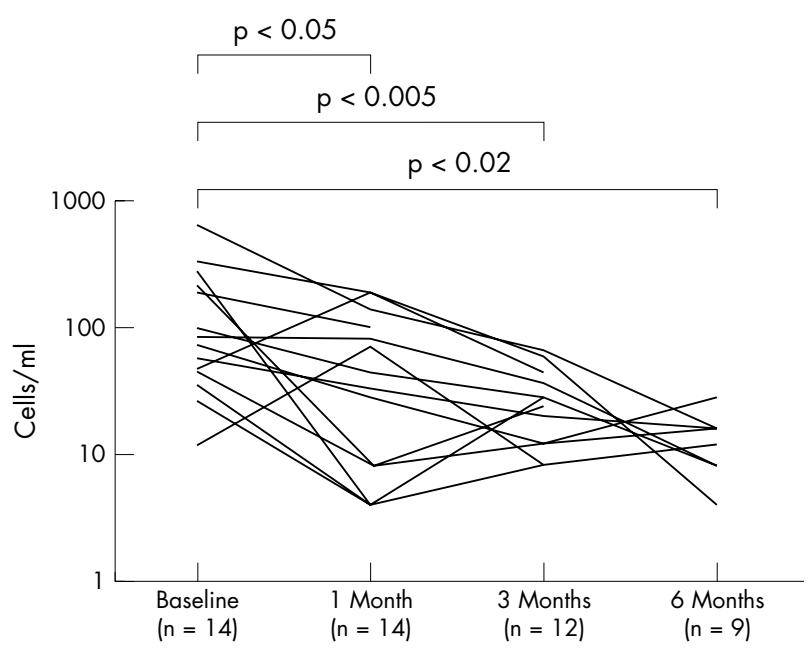

Figure 5 Cell numbers in individual patients with relapse during immunosuppressive therapy. Baseline defines the time point of a first diagnosis of relapse and initiation of treatment. 
immunosuppressive therapy. Cell numbers ranged between 12 and 608 cells/ml (median 76 cells/ml) at baseline, declining to 4 to 186 cells $/ \mathrm{ml}$ at 1 month (median $38 \mathrm{cells} / \mathrm{ml}$, $\mathrm{n}=14 ; \mathrm{p}<0.05$ when compared with baseline), $8-64$ cells $/ \mathrm{ml}$ (median 26 cells $/ \mathrm{ml}, \mathrm{n}=12 ; \mathrm{p}<0.005$ when compared with baseline) at 3 months, and $4-28$ cells/ml (median 16 cells/ $\mathrm{ml}, \mathrm{n}=9 ; \mathrm{p}<0.02$ when compared with baseline) after 6 months (fig 5).

Six patients with new onset vasculitis were also available for follow up. In these patients, Friedman's test demonstrated a significant decline in cell numbers $(p<0.02)$ during immunosuppressive therapy. Cell numbers were 8-216 cells/ $\mathrm{ml}$ (median 56 cells $/ \mathrm{ml}$ ) at baseline, dropping to 4-100 cells/ $\mathrm{ml}$ (median 14 cells $/ \mathrm{ml}$ ) at 1 month, 8-28 cells/ml (median 14 cells $/ \mathrm{ml}$ ) at 3 months, and $4-24$ cells/ml (median 20 cells/ $\mathrm{ml} ; \mathrm{p}<0.05$ when compared with baseline) after 6 months (fig 5).

Six patients with limited granulomatous disease due to WG were available for follow up. Friedman's test (two sided) showed no significant difference $(p=0.28)$ in cell numbers at different time points. In these patients, cell numbers were 16-56 cells $/ \mathrm{ml}$ (median 20 cells $/ \mathrm{ml}$ ) at baseline, 8-32 cells $/ \mathrm{ml}$ (median 16 cells $/ \mathrm{ml}, \mathrm{n}=6$ ) at 1 month, $12-20$ cells $/ \mathrm{ml}$ (median 18 cells $/ \mathrm{ml}, \mathrm{n}=6$ ) at 3 months, and $8-12$ cells $/ \mathrm{ml}$ (median 12 cells $/ \mathrm{ml}, \mathrm{n}=5$ ) after 6 months.

There was a moderately strong but significant correlation of CRP values and CEC numbers (Spearman's rank correlation, $r_{s}=0.434, \mathrm{p}<0.01, \mathrm{n}=56$ ). Finally, there was a strong and significant correlation of BVAS scores and CEC numbers (Spearman's rank correlation, $r_{s}=0.71, \mathrm{p}<0.01, \mathrm{n}=56$ ).

\section{DISCUSSION}

The discovery of ANCA in the $1980 \mathrm{~s}^{7}$ defined a subset of small vessel vasculitides and provided an intriguing concept for their pathogenesis. ${ }^{8}$ The initial enthusiasm for the usefulness of ANCA titres was tempered when increased titres were reported in a variety of infectious disorders. . More importantly, there is only limited correlation between ANCA titres and disease activity, ${ }^{10}$ which led some authors to abandon the ANCA titre as a guide to treatment. ${ }^{11}$ From a clinical point of view, new markers of ANCA associated small vessel vasculitis are therefore eagerly awaited.

CECs have been established as a promising new marker of vascular damage. ${ }^{1}$ We have described the usefulness of this marker in transplantation ${ }^{12-14}$ and ANCA associated small vessel vasculitis. ${ }^{2}$ We reported markedly increased cell numbers in acute vasculitis with subsequent decline during immunosuppressive therapy. In addition, we described a necrotic and procoagulant cell phenotype ${ }^{2}$ and speculated as to the pathogenetic role of these circulating necrotic cells. ${ }^{15}$ We have also shown that patients with infectious disorders do not have increased cell numbers. ${ }^{2}$ Data on other forms of vasculitis are limited, but recent data in Kawasaki's disease suggest that increased numbers of CECs may be common to all vasculitides. ${ }^{16}$

It must be noted, however, that our previous study had limitations. In particular, patients with disease relapse or limited granulomatous disease due to WG were not included in our previous series. In this report, we observed increased numbers of CECs in patients with a relapse of vasculitis. In these patients cell numbers were comparable to those seen in new onset systemic vasculitis. Notably, we included a limited number of patients with new onset disease to ensure that data were comparable with our previous study ${ }^{2}$ despite all the technical changes that had been employed. Patients with limited granulomatous disease due to WG had only slightly increased cell numbers that were not statistically different from those of patients in remission. Using a cut off value of 30 cells $/ \mathrm{ml}$, our test was able to detect active vasculitis with a positive predictive value of $81 \%$ among patients with active vasculitis, limited granulomatous disease, and remission.

These findings suggest that an increased circulating endothelial cell count may distinguish patients with active vasculitis from those with limited granulomatous disease or remission. The clinical usefulness of this finding is considerable, because treatment decisions depend heavily on the presence of active systemic vasculitis. Active vasculitis is difficult to establish in a considerable proportion of patients and our marker may help in such a case. Notably, we found a significant correlation of CEC numbers with BVAS scores and CRP values during follow up. We have previously demonstrated that patients with various forms of systemic infection do not exhibit markedly increased CEC numbers. ${ }^{2}$ Here, we have studied a further six patients with vasculitis with systemic infection who all had low cell numbers. These data give us further confidence that CEC numbers are not markedly increased in infection. We therefore assume that the correlation of CRP values and CEC numbers indicates a correlation with disease activity, not infection. We have previously described a decline in cell numbers during treatment in patients with new onset vasculitis. ${ }^{2}$ Here, we confirm a decline of cell numbers in patients with relapse during immunosuppressive treatment. We assume that immunosuppression rapidly improves endothelial damage, because we have previously demonstrated that cell numbers in renal transplant recipients with acute vascular rejection decline within days of steroid bolus treatment. ${ }^{12}$ Taken together, we believe that these findings support our hypothesis that the number of CECs correlates with disease activity and that a decline of cell numbers after treatment reflects improvement of the endothelial disturbance.

Interestingly, we noted slightly increased numbers of CECs in patients with granulomatous disease, although there we saw no significant decline during immunosuppressive treatment. From a theoretical point of view, vasculitis should be absent in these patients. Conceivably, previous bouts of vasculitis may have contributed to this effect. Continuing low level vasculitis would be another explanation, although in this case cell numbers would be expected to decline with immunosuppressive therapy.

Cell numbers in this study were in the same range as described previously in patients with new onset vasculitis. ${ }^{2}$ The cell numbers reported here were obtained with an improved staining protocol, which has been designed to facilitate counting of CECs. These data give us further confidence that our protocol detects the same cell population as the original methodology. However, our current methodology is still quite labour intensive and would limit widespread use of the CEC count as a marker of vasculitis activity. Consensus about the methodology and cell counting could streamline laboratory techniques and is therefore eagerly awaited. ${ }^{17}$ Our improved protocol has performed well in our experience and is currently being evaluated in a multicentre study. Another factor that needs to be considered is whether CECs remain stable during processing and postal delivery of blood samples. The need to analyse fresh specimens would be an important drawback here. Preliminary data suggest that samples can be stored for up to 4 hours, but the reliability of results beyond that time point remains unclear.

Our study has limitations. There are conflicting results about the predictive value of rising ANCA titres for relapse of vasculitis. Our study was not designed to evaluate this issue nor was it powered to compare the behaviour of ANCA titres with CEC numbers. Further studies should therefore compare CEC numbers and ANCA titres during remission with respect to their predictive value for relapse. 
It has been claimed that CD146 driven immunomagnetic isolation may also capture endothelial progenitor cells, but we showed previously that this is not the case to any significant degree. ${ }^{14}$ The morphology of cells underlines this assumption, in that the severely damaged phenotype described here (figs 1 and 2) and previously ${ }^{2}$ is not observed in progenitor cells. Measurement of endothelial progenitor cells in vasculitis, however, may be of great value. ${ }^{15}$

In conclusion, we have found that markedly increased cell numbers distinguish active vasculitis from granulomatous disease and remission and correlate with disease activity. This marker may be an important tool to aid in the management of ANCA associated small vessel vasculitis. It should now be evaluated in a blinded, prospective fashion.

\section{Authors' affiliations}

A Woywodt, C Goldberg, T Kirsch, K de Groot, U Erdbruegger,

H Haller, M Haubitz, Division of Nephrology, Department of Medicine, Hannover Medical School, Hannover, Germany

Drs Woywodt and Haubitz are supported by a grant from the Deutsche Forschungsgemeinschaft (grant Wo 907/1-1). The funding source had no role in data collection, interpretation, or writing of the manuscript. The authors have no industry affiliations and no conflict of interest. Specifically, there was no affiliation with Biocytex or Dynal, the manufacturers of anti-CD146 antibodies and Dynabeads, respectively.

\section{REFERENCES}

1 Dignat-George F, Sampol J. Circulating endothelial cells in vascular disorders: new insights into an old concept. Eur J Haematol 2000;65:215-20.

2 Woywodt A, Streiber F, de Groot K, Regelsberger H, Haller H, Haubitz M. Circulating endothelial cells as markers for ANCA-associated small-vessel vasculitis. Lancet 2003:361:206-10.

3 Haubitz M, Woywodt A. Circulating endothelial cells and vasculitis. Intern Med 2004;43:660-7.
4 Woywodt A, Goldberg C, Scheer J, Regelsberger H, Haller H, Haubitz M. An improved assay for enumeration of circulating endothelial cells. Ann Hematol 2004;83:491-4.

5 Jennette JC, Falk RJ, Andrassy K, Bacon PA, Churg J, Gross WL, et al. Nomenclature of systemic vasculitides. Proposal of an international consensus conference. Arthritis Rheum 1994;37:187-92.

6 Luqmani RA, Bacon PA, Moots RJ, Janssen BA, Pall A, Emery P, et al. Birmingham Vasculitis Activity Score (BVAS) in systemic necrotizing vasculitis. QJM 1994;87:671-8.

7 Davies DJ, Moran JE, Niall JF, Ryan GB. Segmental necrotising glomerulonephritis with antineutrophil antibody: possible arbovirus aetiology? Br Med J 1982;285:606.

8 Falk RJ, Jennette JC. ANCA are pathogenic-oh yes they are! J Am Soc Nephrol 2002;13:1977-9.

9 Flores-Suarez LF, Cabiedes J, Villa AR, van der Woude FJ, Alcocer-Varela J. Prevalence of antineutrophil cytoplasmic autoantibodies in patients with tuberculosis. Rheumatology (Oxford) 2003;42:223-9.

10 Girard T, Mahr A, Noel LH, Cordier JF, Lesavre P, Andre MH, et al. Are antineutrophil cytoplasmic antibodies a marker predictive of relapse in Wegener's granulomatosis? A prospective study. Rheumatology (Oxford) 2001;40:147-51.

11 Langford CA. Antineutrophil cytoplasmic antibodies should not be used to guide treatment in Wegener's granulomatosis. Clin Exp Rheumatol 2004;22:S3-6.

12 Woywodt A, Schröder M, Gwinner W, Mengel M, Jaeger M, Schwarz A, et al. Elevated numbers of circulating endothelial cells in renal transplant recipients. Transplantation 2003;76:1-4.

13 Woywodt A, Schroeder M, Mengel M, Schwarz A, Gwinner W, Haller H, et al. Circulating endothelial cells are a novel marker of cyclosporine-induced endothelial damage. Hypertension 2003;41:720-3.

14 Woywodt A, Scheer J, Hambach L, Buchholz S, Ganser A, Haller H, et al. Circulating endothelial cells as a marker of endothelial damage in allogeneic hematopoietic stem cell transplantation. Blood 2004; 103:3603-5.

15 Woywodt A, Bahlmann FH, de Groot K, Haller H, Haubitz M. Circulating endothelial cells: life, death and detachment of the endothelial cell layer. Nephrol Dial Transplant 2002;17:1728-30.

16 Nakatani K, Takeshita S, Tsujimoto H, Kawamura Y, Tokutomi T, Sekine I. Circulating endothelial cells in Kawasaki disease. Clin Exp Immunol 2003; 131:536-40.

17 Blann AD, Woywodt A, Bertolini F, Bull TM, Buyon JP, Clancy RM, et al. Circulating endothelial cells. Biomarker of vascular disease. Thromb Haemost 2005;93:228-35. 